\title{
Prevalence of low back pain among females in physiotherapy compared to medicine college in University of Hail
}

\begin{abstract}
Background: Some studies have demonstrated that physiotherapists have a high prevalence of low back pain (LBP). The relationship between physiotherapy students, who are possibly open to the same LBP professional risks as graduates, and LBP has never been established.

Objective: The objective of the study is to evaluate the association between undergraduate physiotherapy study and LBP.

Settings: University of Hail, female Campus.

Methodology: This cross-sectional study was carried out at University of Hail, K.S.A. A survey-based learning was carried out with physiotherapy and medical students. The target population of this study consists of 120 medical and physiotherapy students, where 60 were Medical and 60 were physiotherapy students. The sample was randomly selected from the University of Hail (female campus). The Social Package for Social Sciences (SPSS) version 18.0 (SPSS Inc, Chicago, IL, USA) will be used to analyze the entered data. Descriptive statistics such as Chi square test, $\mathrm{U}$ test, correlation, graphs as well as percentages will be used to describe the participants.
\end{abstract}

Result: Physiotherapy students reported a higher prevalence of LBP when compared with the medical students in all measures. There were no changes between the courses regarding pain intensity and disability.

Keywords: low back pain, occupational diseases, risk factor, physiotherapy, medicine, students
Volume 10 Issue 2 - 202I

\author{
Aisha Ansari, Mohammad Shahid Ali \\ Department of Physiotherapy, College of Applied Medical \\ Sciences, University of Hail, KSA
}

Correspondence: Aisha Ansari, Department of Physiotherapy, College of Applied Medical Sciences, University of Hail, KSA

Received: March 09, 202I | Published: May 04, 2021

\section{Introduction}

There is a common warning that physiotherapists will deliberately interrupt their wellbeing by the distinctive working conditions. Many studies checked high musculoskeletal pain and discomfort among physiotherapists. Such practitioners ' practices are connected to the production of pain. ${ }^{1-3}$ Nearly 60 percent of musculoskeletal injuries in physiotherapists arise as a result of work-related losses. ${ }^{1-5}$ The onset of pain during their undergraduate course is recorded by many physiotherapists.5. Back pain (LBP) is the significant cause of impairment and unemployment, and is expected to affect up to 90 for every cent of people at some point in their lives. ${ }^{1}$

Many studies had also tried to identify and evaluate the contribution of various demographic, physical, socioeconomic, psychological, and occupational factors to the spinal pain advancement. It is notable that $37 \%$ of LBP worldwide is attributed to occupational risk factors, which represent many pain causes that may be preventable. ${ }^{2}$ Several trainings have shown a high incidence of LBP by physiotherapists. ${ }^{3-7}$ Such specialists ' acts are relevant to the progression of this pain. ${ }^{4,5,7}$ It is recorded that in this array up to $60 \%$ of LBP events occur as a magnitude of work-related injuries..$^{3-7}$ Various physiotherapists account for LBP's activation during graduate progress. ${ }^{7}$ In reality, students of physiotherapy may be seen at the same job-related risks as graduates. Including such poor working postures and repeated manual handling, often conducted in challenging environments and with conflicting personal safety practice. We designed a prevalence experiment with physiotherapy and medical students to evaluate the correlation between undergraduate physiotherapy study and LBP, examining possible confounding factors within a logistic regression model, In physiotherapy students, we also intended to validate either LBP is more severe and transducing.

\section{Methodology}

This cross-sectional study focused at Hail University, K.S.A. The target population of this study consists of 120 medical and physiotherapy students, 60 who were medical students and 60 students were physiotherapists. The specimen was randomly chosen from Hail University (the female campus).

A fact sheet was used to compare with medical students to access the predominance of low back pain between several physiotherapy learners. Body mass index, form of pain, origins of low back pain, frequency, number of practical subjects, regular presentations, frequency of lectures and length of pain magnitude, The impact of posture on discomfort, physical activity and job-related effects and the treatment options tried to mitigate LBP.

\section{Measurement}

Body mass was stately without shoes and with negligible clothing to the near $100 \mathrm{~g}$ using a adjusted scale (GIMA Pegaso Electronic Body Scale-Italy). Tallness was stately to the nearest $\mathrm{cm}$ while the subject was in the full standing place minus shoes using a adjusted stadiometer attached to the body weight scale. Body Mass Index was planned as a ratio of weight in $\mathrm{kg}$ by height squared in meters. For measurement of pain, Visual Analog Scale used. 


\section{Statistical analysis}

The Social Package for Social Sciences (SPSS) version 18.0 (SPSS Inc, Chicago, IL, USA) was used to conclude the entered results. Descriptive statistics such as Chi square test, $\mathrm{T}$ test, correlation, graphs as well as percentages were used to describe the results.

\section{Result}

There are total 120 samples where $\mathrm{n}=60$ are from physiotherapy and $\mathrm{n}=60$ were from medical students. Again we divide the students into sub group, like $2^{\text {nd }}, 3$ rd, and $4^{\text {th }}$ year student both from physiotherapy and medical students. In Figure 1 it shows that among physiotherapy students, $n=25$ were from $2^{\text {nd }}$ year, $n=19$ were from $3^{\text {rd }}$ year and $n=16$ were from $4^{\text {th }}$ year. Among medical students, $n=16$ were from $2^{\text {nd }}$ year, $\mathrm{n}=20$ were from $3^{\text {rd }}$ year and $\mathrm{n}=24$ were from $4^{\text {th }}$ year.

In Figure 2 it shows that among physiotherapy students, $16.6 \%$ from $2^{\text {nd }}$ year, $25 \%$ from $3^{\text {rd }}$ year and $25 \%$ from $4^{\text {th }}$ year were experienced Low Back pain compare to medical students, $8.3 \%$ from $2^{\text {nd }}$ year, $13.3 \%$ from $3^{\text {rd }}$ year and $17 \%$ from $4^{\text {th }}$ year were experienced Low Back pain.

\section{Frequency of the Students}

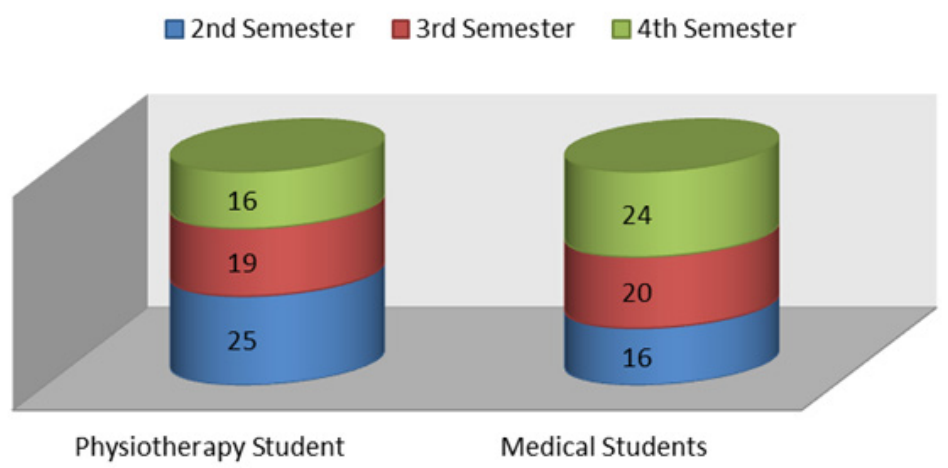

Figure I Frequency of the Students.

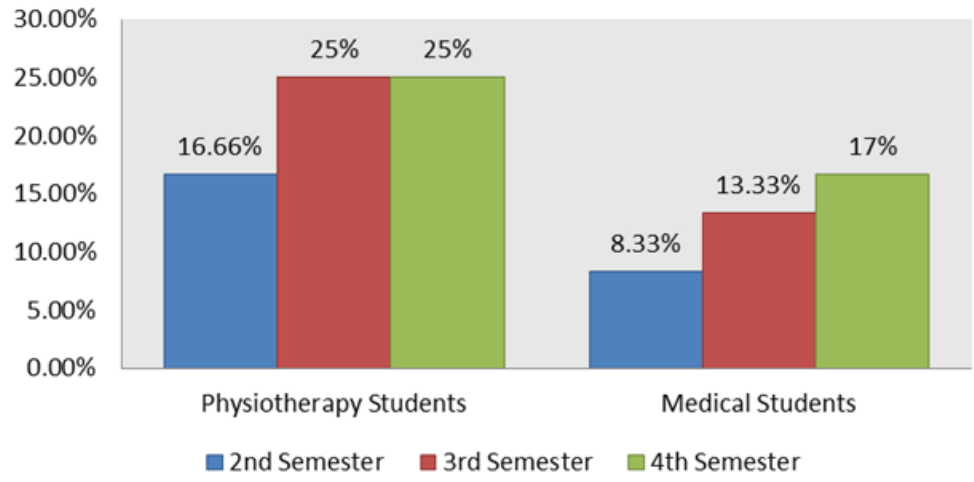

Figure 2 Prevalence of Low Back Pain.

One hundred twenty were evaluated $n=60(50 \%)$ being medical and $n=60(50 \%)$ physiotherapy students. All samples were women $(100 \%)$, the mean age was calculated to be 21.68 years. Table 1 shows the anthropometric features of the sample and the comparisons between the two groups of participants. The physiotherapy students were found to be somewhat younger than medical college group. In physical activity physiotherapy student are more active compare to medical students.

Table I General characteristics of sample and comparisons between programs $(n=120)$

\begin{tabular}{lllll}
\hline & Total & Physiotherapy & Medicine & P \\
\hline Female & $120(100 \%)$ & $60(50 \%)$ & $60(50 \%)$ & $<0.0001$ \\
Age mean & 21.68 & 21.38 & 21.99 & 0.001 \\
Weight mean & 62.1 & 60.42 & 63.82 & 0.008 \\
Height mean & 1.68 & 1.66 & 1.7 & $<0.0001$ \\
BMI & 21.78 & 21.6 & 21.92 & 0.278 \\
Physical activity & & & & \\
Low & $22.90 \%$ & $20.80 \%$ & $25.00 \%$ & \\
Moderate & $38.60 \%$ & $39.10 \%$ & $38.00 \%$ & \\
High & $38.60 \%$ & $40.10 \%$ & $37.00 \%$ & \\
\hline
\end{tabular}


Table 2 presents the characteristics of LBP between the compared groups. In relative to duration of pain in the past year, $11.5 \%$ practiced chronic LBP $(p=0.445)$. It was concluded that among the physiotherapy students sciatica was more likely to be common as compared to medical students $(p=0.003)$. It was found that the pain killers were used by $33.3 \%$ of the students $(p=0.812)$. There were changes between study groups in relation to seeing medical care because of LBP. It was found that the medical students consulted less to the physiotherapist as compared to the other group. Physiotherapy students were more possible to seek medical advice from physiotherapists than medical students $(p=0.025)$.

Table 2 Characteristics of LBP classified by program

\begin{tabular}{llllll}
\hline \multicolumn{1}{l}{ Total } & Physiotherapy & Medicine & $\chi \mathbf{2}$ & P \\
\hline \multicolumn{2}{l}{$\begin{array}{l}\text { Pain duration in present year: } \\
\text { Acute }\end{array}$} & & & & \\
Sub acute & $81.10 \%$ & $78.50 \%$ & $84.40 \%$ & 1.619 & 0.445 \\
Chronic & $7.30 \%$ & $8.20 \%$ & $6.30 \%$ & & \\
& $11.50 \%$ & $13.30 \%$ & $9.40 \%$ & & \\
Classification : & & & & & \\
Pure LBP & $84.70 \%$ & $78.90 \%$ & $91.20 \%$ & 8.953 & 0.003 \\
Sciatic & $15.30 \%$ & $21.10 \%$ & $8.80 \%$ & & \\
Seek care for LBP & & & & & \\
No & $78.40 \%$ & $74.90 \%$ & $82.40 \%$ & 9.319 & 0.025 \\
Yes ,Physician & $15.40 \%$ & $15.80 \%$ & $14.90 \%$ & & \\
Yes, Physiotherapy & $5.30 \%$ & $8.80 \%$ & $1.40 \%$ & & \\
Yes, other & $0.90 \%$ & $0.60 \%$ & $1.40 \%$ & & \\
Use of Medicine & & & & & \\
No & $66.70 \%$ & $66.10 \%$ & $32.70 \%$ & & \\
Yes & $33.30 \%$ & $33.90 \%$ & & & \\
\hline
\end{tabular}

\section{Discussion}

The aim of this cross-sectional analysis was to confirm that physiotherapy students have a higher rate of low back pain. Medical students were selected as a representative community for this. Initially, we found that low back pain was more common in physiotherapy students compared to medical students. We discovered that undergraduate physiotherapy analysis was independently correlated with getting LBP when the variables course, length of study, and female gender were placed into a logistic regression model. To the best of our knowledge, this was the first research to demonstrate a direct connection between undergraduate physiotherapy studies and LBP.

Several studies have been conducted on the burden of work-related musculoskeletal injuries in physiotherapists. ${ }^{3-7}$ According to West and Gardner, ${ }^{7} 16$ percent of physiotherapists were injured as students, while 56 percent said their worst injury happened within the first five years of working as a physiotherapist. The low back is the most frequently affected region. ${ }^{4-7}$ Just $17.7 \%$ of physiotherapy students had never encountered low back pain during their schooling.

Nyland et al. ${ }^{8}$ performed a cross-sectional analysis to evaluate the incidence of low back pain in physiotherapy students. They found that low back pain occurs 27 percent of the time, 44 percent of the time, 63 percent of the time, and 69 percent of the time. ${ }^{8}$ They also determined that, in addition to first-year students, students at all other levels of study were exposed to a knowingly increased risk of low back pain. Finally, the authors contrasted their findings to those of other researchers, questioning whether the undergraduate physiotherapy study might be a risk factor for low back pain. ${ }^{8}$ Our research clearly demonstrated this link, finding that students enrolled in an undergraduate physiotherapy program have a 2.51 times greater chance of experiencing low back pain.

The prevalence of LBP in physiotherapists who have already graduated ranged from 22 to 62.5 percent after one year. ${ }^{4,6,7}$ Manual rehabilitation, such as soft tissue mobilization, shifting dependent patients, aiding patients in gait, provided that manual resistance, assisting in mat exercises, and carrying bulky and awkward equipment are all activities that these practitioners conduct on a daily basis. Campo et al. ${ }^{4}$ performed a one-year longitudinal study of physiotherapists to confirm the prevalence of work-related musculoskeletal injuries in this population. They discovered a 6.6 percent LBP incidence after a year. They also discovered that patient transfers and repositioning were the leading causes of LBP. Our research found that progressive students have a higher risk of experiencing low back pain.

There were no discrepancies in pain intensity and impairment measured by the ODI when physiotherapy students were compared to medical students in terms of the severity of low back pain. However, some of the study's results indicate that LBP may be debilitating for physiotherapy pupils. For example, 33.9 percent of physiotherapy students reported taking medicine for LBP, 25.1 percent needed medical treatment for back pain, and 13.3 percent had chronic LBP, according to the research. Cromie et al. ${ }^{5}$ found that one out of every six physiotherapists changed jobs or left because of occupational musculoskeletal injuries. These results illustrate the need for specific 
educational programs in the physiotherapy setting that address the risk factors for developing LBP as a way to avoid these events in this community. ${ }^{9-15}$

One significant control of our research is that, since it was a cross-sectional study, we were unable to reliably detect whether the frequency of LBP increased during the program. Students who had completed five or more semesters had a higher incidence of low back pain. This suggests that radical students, who are often exposed to realistic practices, are at greater risk. We also had no intention of deciding which tasks in the course were related to the advancement of LBP. Finally, further research could reveal whether preventive measures and educational participation would reduce the risk of LBP among these students.

\section{Conclusion}

The participants of physiotherapy are 2.51 times more likely to develop low back pain in a sample comprising of students of medical and physiotherapy. The span of exposure is also relevant to low back pain, with a 2.55 -fold chance. Several replies suggest that in order to enhance or minimize the impact of low back pain in these students, defensive activities should be conducted out during the undergraduate physiotherapy curriculum.

\section{Acknowledgments}

None.

\section{Funding}

None.

\section{Conflicts of interest}

The authors declare that there is no conflict of interest.

\section{References}

1. Ehrlich GE. Low back pain. Bull World Health Organ.2003;81(9):671-676

2. Punnett L, Pruss-Utun A, Nelson DI, et al. Estimating the global burden of low back pain attributable to combined occupational exposures. Am J Ind Med. 2005;48(6):459-469.
3. Mierzejewski M, Kumar S. Prevalence of low back pain among physical therapists in Edmonton, Canada. Disabil Rehabil.1997;19(8):309-317.

4. Campo M, Weiser S, Koenig KL, Nordin M. Work-related musculoskeletal disorders in physical therapists: a prospective cohort study with 1-year follow-up. Phys Ther. 2008;88(5):608-619.

5. Cromie JE, Robertson VJ, Best MO. Work-related musculoskeletal disorders in physical therapists: prevalence, severity, risks, and responses. Phys Ther. 2000;80(4):336-351.

6. Molumphy M, Unger B, Jensen GM, et al. Incidence of work-related low back pain in physical therapists. Phys Ther.1985;65(4):482-486.

7. West DJ, Gardner D. Occupational injuries of physiotherapists in North and Central Queensland. Aust J Physiother.2001;47(3):179-186.

8. Nyland LJ, Grimmer KA. Is undergraduate physiotherapy study a risk factor for low back pain? A prevalence study of LBP in physiotherapy students. BMC Musculoskelet Disord. 2003;4:22.

9. Gorenstein C, Andrade L, Vieira Filho AH, et al. Psychometric properties of the Portuguese version of the Beck Depression Inventory on Brazilian college students. J Clin Psychol. 1999;55(5):553-562.

10. Craig CL, Marshall AL, Sjostrom M, et al. International physical activity questionnaire: 12-country reliability and validity. Med Sci Sports Exerc. 2003;35(8):1381-1395.

11. Guedes DP, Lopes CC, Guedes JE. Reprodutibilidade e validade do Questionário Internacional de Atividade Física em adolescentes. Rev Bras Med Esporte. 2005;11(2):151-158.

12. Kuorinka I, Jonsson B, Kilbom A, et al. Standardised Nordic questionnaires for the analysis of musculoskeletal symptoms. Appl Ergon. 1987;18(3):233-237.

13. Dionne CE, Dunn KM, Croft PR, et al. A consensus approach toward the standardization of back pain definitions for use in prevalence studies. Spine. 2008;33(1):95-103.

14. Fairbank JC, Pynsent PB. The Oswestry Disability Index. Spine. 2000;25(22):2940-2952.

15. Vigatto R, Alexandre NM, Correa Filho HR. Development of a Brazilian Portuguese version of the Oswestry Disability Index: cross-cultural adaptation, reliability, and validity. Spine. 2007;32(4):481-486. 